\title{
A Study To Assess Immunization Status In 12 -23 Months Old Children Coming To Pediatrics Opd Of Gmch
}

\author{
Dr. Prabhat Singh Baghel (Post Graduate Student); Dr. GayatriBezboruah \\ (Professor\& Head); \\ Dr. Indira Das (Asst. Professor), Dr. Niladri Sekhar Bhunia(Post graduate \\ student) \\ Department Of Pediatrics, Gauhati Medical College, Guwahati (Assam)
}

\begin{abstract}
Aims and Objectives:Assess the immunization status of children age group between 12-23 months from Kamrup Metro district. To identify and explore the factors affecting immunization status in children of Kamrup Metro and reasons for drop out from vaccinations.

Design:It is hospital based study conducted in OPD, Guwahati medical college \&hospital, Guwahati for lyear from $1^{\text {st }}$ June 2012 to $31^{\text {st }}$ May 2013.

Participants: Children between 12-23 months of age belonging to Kamrup Metro district of Assam, who do not have immunosuppressive diseases \& not on steroids are included in the study.

Results: $64.17 \%$ of children were fully immunized, $30.12 \%$ and $5.70 \%$ were partially and unimmunized respectively.BCG has maximum coverage (93.93\%) \& minimum for measles (64.88\%). Hindus were better immunized $70.18 \%$ compared to other religions. Parenteral age and education also significantly proportional to immunization status. Immunization increases with increase in socioeconomic status (91.66\% for class 1$)$. Increase in birth order decreases chances of immunization. Practices like hospital deliveries and health care workers visits promote vaccination. Reasons for dropout were sickness, fear of side effects and family problems. Conclusion:Immunization coverage for children is still lagging behind significantly mainly because of social and economic reasons. Literacy has positive effect on immunization. Hence there is a lot of scope of improvement by spreading awareness and improving the living standards and providing better healthcare facilities which will in turn lead to complete immunization coverage and safe childhood.
\end{abstract}

\section{Introduction}

Immunization has been one of the most significant, cost effective \& stimulatory public health intervention. Immunization forms the major focus of child survival programs throughout the world. ${ }^{1}$ Roughly 3 million children die each year of vaccine preventable diseases (VPDs) with a disproportionate number of these children residing in developing countries. ${ }^{2}$ In India, immunization services are offered free in public health facilities, but, despite rapid increases, the immunization rate remains low in some areas. According to the National Family Health survey (NFHS-3), in India only 44\% of children aged 1-2 years have received the basic package of 6 vaccines. ${ }^{3}$

In Assam, IMR is 64 as comparison to national 53 per 1000 live birth.According to data of state programme implementation 2011-12,there was increased performance of immunization in year 2007-08 as compared to 2006-07 but decline in performance was noted in year 2008-09 followed by sharp decline in year 2010-11. ${ }^{4,5}$ Kamrup metro district of Assam also experienced decline in fully immunization performance from year 2005-06 to 2010-11.,5

Fully Immunization Performance for Last Few Years inKamrupMerto District ${ }^{5}$

\begin{tabular}{|l|l|}
\hline Year & Percentage \\
\hline $2005-06$ & 81.51 \\
\hline $2006-07$ & 71.65 \\
\hline $2007-08$ & 83.81 \\
\hline $2008-09$ & 83.29 \\
\hline $2009-10$ & 80.86 \\
\hline $2010-11$ & 58.86 \\
\hline
\end{tabular}

Hence, this study targeted for immunization status in 12-23 months of children in kamrup metro district and the various factors affecting it.

\section{Material And Methods}


Setting - A hospital based survey conducted in OPD of GMCH, Guwahati for 1 year.

Time period- June 2013- May 2014Study population- children of 12-23 months of age group.

Inclusion criteria: Children only belonging to Kamrup Metro district of age of $12-23$ months free from immunosuppressive disease \& not receiving steroids are included in study.

Method: This is observational study done using a predesigned questionnaire among 761 children of age group of 12-23 months belonging to Kamrup Metro. Interview done using predesigned questionnaire with parents of children coming to pediatric OPD of GMCH.

- Fully immunized: children fully immunized with all doses of 5 vaccines recommended in NIS (National Immunization schedule).

- Partially immunized: children not immunized with all the vaccine doses of NIS.

- Unimmunized: children not received even a single vaccine dose.

Data collected and analyzed.

\section{Results}

- Table 1 shows that out of 561 children, 360 children $(64.17 \%)$ were fully immunized, 169children $(30.12 \%)$ were partially immunized \& $32(5.70 \%)$ children were unimmunized.

Table 1 - Immunization Status of Children

\begin{tabular}{|l|l|l|l|}
\hline S.N. & Status & Total & percentage \\
\hline 1. & Fully immunized & 360 & $64.17 \%$ \\
\hline 2. & Partial immunized & 169 & $30.12 \%$ \\
\hline 3. & Unimmunized & 32 & $5.70 \%$ \\
\hline & Total & 561 & $100 \%$ \\
\hline
\end{tabular}

- Table 2 shows that BCG has maximum coverage(93.93\%) \& minimum for measles (64.88\%).OPV-0 have 526(93.76\%),OPV-1 have 508(90.55\%),OPV-2 have 493(87.87\%),OPV-3 have 450(80.21\%),Hep-B have 518(92.33\%),Hep-B1 have 495(88.23\%),Hep-B2 have 466(83.06\%),Hep-B3 have 432(77.00\%)DPT-1 have $499(88.94 \%)$, DPT-2 have 470(83.77\%) DPT-3 have 430(76.64\%) \& measles having 364(64.88\%) coverage.

Table 2 - Status Of Individual Vaccines

\begin{tabular}{|l|l|l|l|}
\hline S.N. & Vaccine & Number of children vaccinated & Percentage \\
\hline 1 & B.C.G & $527 / 561$ & $93.93 \%$ \\
\hline 2 & O.P.V.-0 & $526 / 561$ & $93.76 \%$ \\
\hline 3 & O.P.V.-1 & $508 / 561$ & $90.55 \%$ \\
\hline 4 & O.P.V.-2 & $493 / 561$ & $87.87 \%$ \\
\hline 5 & O.P.V.-3 & $450 / 561$ & $80.21 \%$ \\
\hline 6 & Hepatitis B & $518 / 561$ & $92.33 \%$ \\
\hline 7 & Hepatitis B-1 & $495 / 561$ & $88.23 \%$ \\
\hline 8 & Hepatitis B-2 & $466 / 561$ & $83.06 \%$ \\
\hline 9 & Hepatitis B-3 & $432 / 561$ & $77.00 \%$ \\
\hline 10 & D.P.T.-1 & $499 / 561$ & $88.94 \%$ \\
\hline 11 & D.P.T.-2 & $470 / 561$ & $83.77 \%$ \\
\hline 12 & D.P.T.-3 & $430 / 561$ & $76.64 \%$ \\
\hline 13 & Measles & $364 / 561$ & $64.88 \%$ \\
\hline
\end{tabular}

- Table 3 shows $63.9 \%$ fully immunized males while $63.2 \%$ females. $27.9 \%$ males and $32.8 \%$ females were partially immunized. $3.89 \%$ males and $7.9 \%$ females were unimmunized.

No significant correlation was found between sex of the child and immunization status.

Table 3 Immunization Based On Sex of Child

\begin{tabular}{|l|l|l|l|l|l|l|}
\hline S.N. & Immunization & \multicolumn{2}{l|}{ Males } & \multicolumn{2}{l|}{ Females } & Total \\
& Status & \multicolumn{2}{l|}{} & \\
\hline & & Cases & Percentage & Cases & percentage & \\
\hline 1 & Fully immunized & 200 & 64.93 & 160 & 63.24 & 360 \\
\hline 2 & Partially immunized & 86 & 27.92 & 83 & 32.80 & 169 \\
\hline 3 & Unimmunized & 12 & 3.89 & 20 & 7.90 & 32 \\
\hline & Total & 308 & 100 & 253 & 100 & 561 \\
\hline
\end{tabular}

- In the study population of 561 children, 369 were Hindus, 177 Muslim, 12 Christian and 3 belonged to other religions. $70.18 \%$ of Hindus were fully immunized, $25.74 \%$ and $4.06 \%$ were partially immunized and unimmunized. Among Muslims 51.4\%, 38.9\% and 9.6\% were fully, partially and unimmunized. $66.7 \%$ of 
Christians were fully immunized while $33.3 \%$ were partially immunized. P value was 0.001 which was found to be significant.

- $46.66 \%$ of children with their mother $<20$ years age were fully immunized, while $26.66 \%$ were partially and $26.66 \%$ were unimmunized. Among 20-29 years, $64.41 \%, 28.31 \%$ and $7.27 \%$ were fully, partially and unimmunized. Among 30-39 years, $65.54 \%$ and $34.45 \%$ were fully and partially immunized. And among $>40$ years, $66.66 \%$ and $41.66 \%$ were fully and partially immunized. P value for the above data was 0.001 which was found to be significant.

- $40.4 \%$ children of illiterate mother were fully immunized while it was $80 \%$ for women who completed postgraduation. . Rate of partial and unimmunized children decreased with increase in maternal education. $\mathrm{P}$ value (0.001) was significant.

- Immunization also was affected by father`s age. Among 20-29 years full immunization was seen in $63.44 \%$, while $27.58 \%$ and $8.95 \%$ were partially and unimmunized. Among 30-39years age group, full, partial and non-immunization was seen in $65.68 \%, 28.75 \%$ and $5.55 \%$ respectively.

- Percentage immunization increases with the literacy level of the father. Least (31.11\%) was among illiterate, maximum $(100 \%)$ was among children with fathers studied up to post-graduation. $\mathrm{P}$ value of 0.0001 was highly significant.

- Immunization status was directly proportional to the socioeconomic status of the family. $91.66 \%$ of class I, $72.92 \%$ of class II, $64.61 \%$ of class III, $58.89 \%$ of class IV, and $15.15 \%$ of class V received complete immunization.

- No significant correlation was found between immunization and type of family.

- Immunization status decreased with increases in birth order. However it was slightly more for $2^{\text {nd }}$ child compared to $1^{\text {st }}$.

- Maximum immunization coverage was seen in private hospital deliveries (80\%), followed by govt. hospital $(65.13 \%)$ and least in home deliveries $(27.5 \%)$. P value of 0.0001 was highly significant.

- Increase in immunization coverage with increase in number of health worker visits was seen. Immunization status for no visits was $62.23 \%, 63.15 \%$ for $1-2$ visits, $71.87 \%$ for $3-5$ visits and $91.66 \%$ for $>5$ visits. $P$ value of 0.0478 was significant.

- There was a decrease in immunization coverage with increase in distance of residence and immunization center. $70.42 \%$ fully immunized when distance was $1-2 \mathrm{~km}, 63.82 \%$ when it was $3-5 \mathrm{~km}$ and $48.19 \%$ for $>5 \mathrm{~km}$. $\mathrm{p}$ value of 0.0017 was significant.

Top 3 reasons for partial immunizations were

1. Child was ill

2. Fear of side effects

3. Family problems including mother illness

\section{Discussion}

In this study it was observed that about $64.2 \%$ of the children were fully immunized, $30.1 \%$ partially immunized and $5.7 \%$ were unimmunized among the study group. This was comparable to CES-RRC-NE 2009, DLHS 07-08 and NRHM 10-11 data where percentage of fully immunized children in Kamrup Metro district were $77.77 \%, 73.5 \%$ and $58.86 \%$ respectively. $^{4}$

Other similar study by Malkaret $\mathrm{al}^{6}$ showed $78.6 \%$ full immunization, $20.5 \%$ partial and $0.95 \%$ unimmunized children. Sharma et $\mathrm{al}^{7}$ showed $81 \%, 17.6 \%$ and $1.4 \%$ respectively for each of $\mathrm{d}$ above mentioned categories.

According to NFHS III Coverage of BCG, DPT, and polio (except "at birth" polio dose) is much higher than all other vaccines. Although DPT and polio vaccinations are given at the same time as part of routine immunization programme, the coverage rates are higher for polio than for DPT (all three doses), undoubtedly because of the pulse polio campaigns. This study showed maximum coverage for BCG and minimum for measles. Other studies Sharma et $\mathrm{al}^{7}$, Chabbra et $\mathrm{al}^{8}$, Singh et $\mathrm{al}^{9}$ and Bhatia et al ${ }^{10}$ had similar results.

Our study was comparable to study conducted by Pragathiet $\mathrm{al}^{11}$, stating that the dropout rate increases with subsequent vaccination.

This indicates that the enthusiasm of the parents generated with the birth of the child is not maintained, which, in turn suggests lack of sustained health education activity by the concerned health workers.

The female-male ratio is substantially below unity in India (0.93). A higher value is accorded to the male child in our society. Thus the girl child is one of the most marginalized and deprived groups. In our study no significant difference was seen between immunization status of males (64.9\%) and females (63.2\%). Which was in contrast to study conducted by J.Yadavet $\mathrm{al}^{12}$, Malinikar et $\mathrm{al}^{13}$, Nirupam et al ${ }^{14}$ also stated better immunization of males. 
The 2009-10 UNICEF survey ${ }^{15}$, UNICEF (2005) survey across 22 states $^{16}$, Ministry of Health and Family Welfare coverage evaluation survey during 2001-02 $2^{17}$ and ICMR survey (1999) reported better immunization status on male child.

On the basis of religion Hindus were found to be better immunized. Results were comparable with studies by Yadavet $\mathrm{al}^{12}$, Borooah ${ }^{18}$ in 2004 , Dalal et $\mathrm{al}^{19}$ and Phukun et $\mathrm{al}^{20}$.

Mother's age has a great impact on immunization because age at marriage and having children are directly related to education of and occupation of mother. Mothers with higher level of education tend to understand the scientific information more easily than those with lower level of education. Literate mother will know the schedule of vaccines and their benefits better than illiterate. Immunization status was found to be proportional

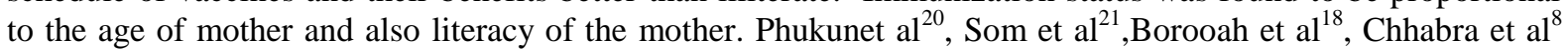
studied impact of mothers education on immunization and came up with similar results. ICMR 1999 survey also reported the same

Father's age and education also had similar proportional relationship as that of mothers. It was reported in UNICEF survey 2005, ICMR 1999 survey, and the study done by Chhabraet $\mathrm{al}^{7}$, Som et $\mathrm{al}^{21}$, Phukun et $\mathrm{al}^{20}$, and MM Sanghvi ${ }^{22}$.

The socioeconomic status of a family usually defines the living standard and the health facilities enjoyed by that family. The study population was divided into 5 classes according to socioeconomic status based on modified Kuppuswamy scale $(2011)^{27}$. .Maximum immunization coverage was seen in Class I $(91.66 \%)$ and minimum in Class V $(15.15 \%)$. Dalalet $\mathrm{al}^{19}$, Inamdar et $\mathrm{al}^{24}$, Malkar et $\mathrm{al}^{6}$ and Bholanath et $\mathrm{al}^{25}$ also observed similar findings.

Family is a unit of social service as well as comprehensive medical care. In the present study, complete immunization was seen in $63.6 \%$ in nuclear family and $66.1 \%$ in joint family

Caring for multiple children can create a unique barrier to vaccination. There is a strong association between use of immunization service \& family planning. It was observed that first child had less chances of being completely immunized than that of second. It might be because of more sensitization and awareness of parents regarding immunization of second and third child as compared to first due to their previous experiences about it.

Similar results were shown by studies by Dalalet $\mathrm{al}^{18}$, Malkar et $\mathrm{al}^{6}$ and Sanghvi et $\mathrm{al}^{22}$. The NFHS-3 data ${ }^{26}$ and CES 2009 by UNICEF ${ }^{15}$ showed a trend of declining vaccination with increasing birth order.

Hospital staff plays an important role in educating parents regarding the need of immunization of children. Significant increase in immunization status in hospital deliveries was observed. Our study is supported by works of Sanghviet $\mathrm{al}^{22}$, Malkar et $\mathrm{al}^{6}$, Chhabra etal ${ }^{8}$.

Immunization coverage is proportional to increasing number of health worker visits. And inversely proportional to distance of house to immunization center. ICMR 1999 had similar findings. Mohan $\mathrm{P}^{27}$ and Phukunet al ${ }^{20}$ also supported our results.

\section{Conclusion}

Our study included children of age group 12-23 months belonging to Kamrup Metro who came in pediatric OPD of our hospital using predesigned questionnaire over a period of 1 year. It was noted that social evils like practice of early marriage of both girls and boys, lack of family planning, lack of proper education and basic awareness, prevalence of customs in particular religion etc. decreases immunization coverage significantly. On the other hand practices like institutional deliveries, health workers' home visits, rise in literacy level etc. increases the chances of complete vaccination for the child. Hence to make the health care facilities in India in par with the standards recommended by WHO and with the world it is necessary to make significant improvements in the above mentioned areas.

\section{Biblography}

[1]. World Health Organization. The World health report: 2005: make every mother and child count. Available from: http://www.who.int/whr/2005/en/index.html.

[2]. Kalaivani K, Mathiyazhagan T, Patro BC. Editorial. News Lett Nat InstHlthFam Welfare 2006; 8: 1-2.4

[3]. Pandey RP, Yazbeck AS. Beyond National Averages for Immunization in India: Income, Gender, and Regional Inequalities. 1999. Page 5-7.

[4]. Assam,national rural health mission ,state health programme data

[5]. Assam, national rural health mission, state health programme data, table showing survey results.

[6]. Malkar VR, Khadilakar H, Lakde RN, Joge US, Choudhari SG. Assessment of Sociodemographic Factors Affecting Immunization Status of Children in Age Group of 12-23 Months in a Rural Area. Indian Medical Gazette — MAY 2013

[7]. Sharma B, Mahajan H, Vehal GD. Immunization Coverage: Role of Sociodemographic Variables. Advances in Preventive Medicine. Volume 2013 (2013), Article ID 607935, 5 pages

[8]. Chhabra P, Nair P, Gupta A, Sandhir M, Kannan AT. Immunization in urbanized villages of Delhi. Indian J Pediatr 2007; 74 (2):131-134.

[9]. Singh MC, Badole CM, Singh MP. Immunization coverage. KAP of mother regarding immunization in rural areas.ind. jr of public medicine1992,6(3).153-155

[10]. Bhatia V, Swami HM, Rai SR, Gulati S, Verma A. immunization status in children. Indian J Pediatr 2004; 71:313-315. 
[11]. Pragathi, Phukan RK, Barman MP, Mahanta J. Factors associated with immunization coverage of children in Assam, India: over the first year of life. J Trop Pediatr. 2009; 55:249-52.

[12]. Yadav R J, Singh P. Immunization status of children and mothers in the state of Madhya Pradesh. Indian Journal of Community Medicine 2004; 29(3):147-48Chhabra P, Nair P, Gupta A, Sandhir M, Kannan AT. Immunization in urbanized villages of Delhi. Indian J Pediatr 2007; 74 (2):131-134.

[13]. Kar M., Reddiah V.P, Kant S.; Primary immunization status of children in slum areas of South Delhi -The challenge of reaching the urban poor. Indian J. Community Medicine; 2001: 26:151-4.

[14]. Nirupam S. UIP in Sarojini Nagar block of Lucknow district. Indian J Comm Med 1991; 16(2):82-84.

[15]. Department of Family Welfare, Ministry of Health and Family Welfare, Government of India. Coverage Evaluation Survey - 2002. IPPI, Routine Immunization and Maternal Care. National Report. Available from: http://202.71.128.172/nihfw/nchrc/sites/default/files/Coverage\%20Evaluation\%20Survey\%20\%202002\%2020IPPI,\%20Routine\%20Immunization\%20and\%20Maternal\%20Care\%20\%20

[16]. National\%20Report_0_0.pdf. Accessed on 27 December 2011

[17]. No authors listed. Coverage Evaluation Survey. All India Report $2005 . \quad$ Available from: http://202.71.128.172/nihfw/nchrc/sites/default/files/All\%20India\%20Report \%202005\%20Coverage\%20Evaluation\%20Survey1044_2.pdf. Accessed on 27 December 2011Dalal A, Silveira MP. Imunization status of children in Goa. Indian Pediatr. $2005 ; 42: 401-2$

[18]. Department of Family Welfare, Ministry of Health and Family Welfare, Government of India. Coverage Evaluation Survey - 2002. IPPI, Routine Immunization and Maternal Care. National Report. Available from: http://202.71.128.172/nihfw/nchrc/sites/default/files/Coverage\%20Evaluation\%20Survey\%20-\%202002\%2020IPPI,\%20Routine\%20Immunization\%20and\%20Maternal\% 20Care\%20-\%20National\%20Report_0_0.pdf. Accessed on 27 December 2011

[19]. Borooah VK. Gender bias among children in India in their diet and immunization against disease. SocSci Med. 2004; 58:1719-31

[20]. Dalal A, Silveira MP. Imunization status of children in Goa. Indian Pediatr. 2005;42:401-2

[21]. Phukan RK, Barman MP, Mahanta J. Factors associated with immunization coverage of children in Assam, India: over the first year of life. J Trop Pediatr. 2009; 55:249-52.

[22]. Som S, Pal M, Chakrabarty S, Bharati P. Socioeconomic impact on child immunization in the districts of West Bengal, India. Singapore Med J. 2010; 51:406-12.

[23]. Sanghvi MM. Study of socio demographic factors influencing vaccination status of children in dared industrial area of Jamnagar. Int J Res Med. 2013; 2(4);43-47

[24]. Kuupuswamy scale modified version 2011,ind. Jr of comm medicine

[25]. MadhuriInamdar, SaurabhPiparsania, SavitaInamdar, Kuldeep Singh. Immunization status of school children of Indore hailing from different socioeconomic Status. National Journal of Community Medicine July-Sept 2011; Vol 2 Issue 2: 216-20.

[26]. A study on determinants of immunization coverage among 12-23 months old children in urban slums of Lucknow district, India, Indian jr. of medical science. Year : 2007 | Volume : 61 | Issue : 11 | Page : 598-606.

[27]. International Institute for Population Sciences (IIPS) and Macro International. National Family Health Survey (NFHS-3), 2005-06: India. Mumbai: IIPS; 2008

[28]. Mohan P. Inequities in coverage of preventive child health interventions: the rural drinking water supply program and the universal immunization program in Rajasthan, India. Am J Public Health. 2005; 95:241-4. 